\title{
ENSINO SUPERIOR EM ENFERMAGEM EM TEMPOS DE PANDEMIA DA COVID-19
}

\author{
HIGHER EDUCATION IN NURSING IN TIMES OF A COVID-19 PANDEMIC
}

\section{EDUCACIÓN SUPERIOR EN ENFERMERÍA EN TIEMPOS DE PANDEMIA COVID-19}

\begin{abstract}
Jhonata Correa ${ }^{1}$, Sarah Lais Rocha ${ }^{2}$, Renata Campos de Sousa Borges ${ }^{3}$, Adams Brunno Silva ${ }^{4}$, Mariana Souza de Lima ${ }^{5}$, Gleiciane Moraes Gonçalves ${ }^{6}$, Cintia Yolette Urbano Pauxis Aben-Athar Valentim ${ }^{7}$, Geyse Aline Rodrigues Dias ${ }^{8}$, Gleivison Cunha Teles $^{9}$, Maicon de Araujo Nogueira ${ }^{10}$, Aline Maria Pereira Cruz Ramos ${ }^{11}$
\end{abstract}

Submetido em: $14 / 07 / 2021$

e27560

Aprovado em: 17/08/2021

https://doi.org/10.47820/recima21.v2i7.560

\section{RESUMO}

Para mitigar a transmissão do vírus da COVID-19, adotaram-se o distanciamento social e o Ensino Remoto Emergencial (ERE) no Brasil, e essa transição ocorreu de forma abrupta, gerando impactos no ensino superior de enfermagem. O objetivo deste estudo é analisar o ERE na educação superior pública e privada no Estado do Pará no contexto da pandemia da Covid-19, na perspectiva dos acadêmicos de enfermagem. Trata-se de um estudo descritivo exploratório, do tipo survey, de abordagem quantitativa, realizado entre setembro e dezembro de 2020. Para recrutamento de participantes utilizou-se da técnica Bola de Neve, com o link do questionário online compartilhado nas redes sociais. $O$ questionário continha 24 questões referentes a três domínios: caracterização dos participantes; avaliação do acesso à Internet; e o ensino-aprendizagem em Enfermagem durante a pandemia. Identificou-se uma difícil transição do ensino tradicional presencial para o ERE entre os dois grupos, com melhor acessibilidade, maior impacto negativo do ERE nos acadêmicos de IES privada. O impacto do ERE na formação do profissional enfermeiro foi divergente, e a visão positiva entre os acadêmicos de IES privada foi relacionada ao término das atividades, enquanto a negativa, àqueles da IES pública gostariam de ter a prática clínica assegurada.

PALAVRAS-CHAVE: Educação em Enfermagem. Ensino Remoto. Covid-19.

\footnotetext{
${ }_{1}^{1}$ Universidade da Amazônia - UNAMA

${ }^{2}$ Doutoranda pelo programa de pós-graduação doutorado profissional em Ensino e Saúde na Amazônia pela Universidade do Estado do Pará. Docente da Faculdade dos Carajás.

Coordenadora e docente do Curso de Graduação em Enfermagem na Faculdade dos Carajás.

${ }^{3}$ Mestre em Ensino em Saúde na Amazônia, pela UEPA, Belém-PA, na Linha de Pesquisa: Fundamentos e metodologias em ensino na saúde na Amazônia, em 2019. Doutoranda no Programa Pós-graduação Doutorado Profissional em Ensino em Saúde na Amazônia, pela UEPA,

${ }^{4}$ Especialização em pós-graduação em cardiologia pela sociedade nacional de educação ciência e tecnologia Ltda., Brasil (2011) - Membro de comissão do hospital Ophir Loyola.

${ }^{5}$ Mestrado em enfermagem pela Universidade Federal do Pará (2017). Especialista em Urgência e Emergência (UFPA/2017), Gestão e Auditoria (IPOG/2016) e Segurança do Paciente e Controle de Infecção Hospitalar (Dalmass/2020). Doutoranda do Programa de Pós-Graduação em Genética e Biologia Molecular (PPGBM- UFPA).

${ }^{6}$ Acadêmica de enfermagem na Universidade da Amazônia (UNAMA) e formada no Curso Técnico em Informática pelo Instituto Federal de Educação, Ciência e Tecnologia do Pará. Voluntária no PIBIC-Unama e Ex-bolsista Discente do Projeto de Pesquisa Socioterritorial de Segurança Pública.

${ }^{7}$ Doutora (2018) e Mestre (2015) em Biologia de Agentes Infecciosos e Parasitários/Área de Concentração em Epidemiologia e Controle do Programa de Pós-graduação em Biologia de Agentes Infecciosos e Parasitários (PPGBAIP) do Instituto de Ciências Biológicas (ICB) da Universidade Federal do Pará (UFPA). Graduada em Enfermagem pela Escola de Enfermagem Magalhães Barata da Universidade do Estado do Pará (2012). É docente efetiva da Faculdade de Enfermagem da Universidade Federal do Pará.

${ }^{8}$ Graduada em Enfermagem, Bacharelado e Licenciatura pela Faculdade de Enfermagem da Universidade Federal do Pará. Especialista em Avaliação de Serviços de Saúde-Ênfase em Educação Permanente pela Universidade Aberta do SUS/Universidade Federal de Ciências da Saúde de Porto Alegre. Mestre em Enfermagem pelo Programa de Pós-graduação em Enfermagem da UFPA. Atualmente é professora da atividade curricular Processos Educativos em Enfermagem I da Faculdade de Enfermagem da UFPA. Tem afinidade pela pesquisa e pela docência principalmente nas áreas de Educação em saúde, Educação na Saúde, Educação em Enfermagem e Enfermagem em Saúde Coletiva.

${ }_{9}$ Graduando do Curso Superior em Enfermagem pela Universidade da Amazônia

${ }^{10}$ Mestrado Profissional em Ensino em Saúde na Amazônia (ESA), Universidade do Estado do Pará (UEPA). Doutorando no Programa de Pós-Graduação Stricto Sensu, Doutorado Profissional em Ensino em Saúde na Amazônia (ESA), UEPA.

${ }^{11}$ Enfermeira graduada pela Universidade do Estado do Pará. Residência em enfermagem oncológica pela universidade do Estado do Pará, hospital Ophir Loyola. Mestrado e doutorado em genética e biologia molecular pela universidade federal do Pará. Pós-doutorado em oncologia.
} 


\section{RECIMA21 - REVISTA CIENTÍFICA MULTIDISCIPLINAR ISSN 2675-6218}

\section{ABSTRACT}

To mitigate the transmission of the COVID-19 virus, social distancing and Emergency Remote Education (ERE) were adopted in Brazil, this transition occurred abruptly, generating impacts on higher education in nursing. The aim of this study is to analyze the ERE in public and private higher education in the state of Pará during the context of the Covid-19 pandemic from the perspective of nursing students. This is a descriptive exploratory study, of the survey type, with a quantitative approach, carried out between September and December 2020. To recruit participants, the Snowball technique was used, where the link to the online questionnaire was shared on social networks. The questionnaire contained 24 questions referring to 3 domains: characterization of the participants; evaluation of internet access and nursing teaching-learning during the pandemic. A difficult transition from traditional face-to-face teaching to ERE was identified between the two groups, with better accessibility, greater negative impact of ERE on private HEI students. The impact of the ERE on the training of professional nurses was divergent, whose positive view among academics from private HEls was related to the end of activities, while negative to those from the public sector would like to ensure the assured clinical practice.

KEYWORDS: Nursing Education. Remote Teaching. Covid-19.

\section{RESUMEN}

Para mitigar la transmisión del virus COVID-19, en Brasil se adoptó el distanciamiento social y la Educación Remota de Emergencia (ERE), esta transición ocurrió de manera abrupta, generando impactos en la educación superior en enfermeira. El objetivo de este estudio es analizar los ERE en la educación superior pública y privada en el estado de Pará durante el contexto de la pandemia Covid-19 desde la perspectiva de los estudiantes de enfermería. Se trata de un estudio exploratorio descriptivo, tipo encuesta, con enfoque cuantitativo, realizado entre septiembre y diciembre de 2020. Para la captación de participantes se utilizó la técnica Snowball, donde se compartió en redes sociales el enlace al cuestionario online. El cuestionario contenía 24 preguntas referidas a 3 dominios: caracterización de los participantes; evaluación del acceso a internet y la enseñanzaaprendizaje de enfermería durante la pandemia. Se identificó una transición difícil de la enseñanza presencial tradicional a ERE entre los dos grupos, con mejor accesibilidad, mayor impacto negativo de ERE en los estudiantes privados de IES. El impacto de los ERE en la formación de enfermeras profesionales fue divergente, cuya visión positiva entre los académicos de las IES privadas se relacionó con el fin de las actividades, mientras que la negativa para los del sector público quisiera asegurar la práctica clínica asegurada.

PALABRAS CLAVE: Educación en enfermeira. Enseñanza remota. Covid-19.

\section{INTRODUÇÃO}

Inicialmente, a doença causada por coronavírus (COVID-19) foi reportada na cidade de Wuhan, na China, em dezembro de 2019 (SCHMIDT et al., 2020; DUARTE et al., 2021) e depois disseminou-se a vários países. Na Região Norte brasileira registrou-se a incidência acumulada de 9.339,5 casos/100 mil habitantes e mortalidade de 236,0 óbitos/100 mil habitantes, onde o Estado do Pará apresentou um total 561.798 casos confirmados e 15.701 óbitos decorrentes da COVID-19 (BRASIL, 2021).

A transmissão do vírus ocorre pela disseminação de gotículas e aerossóis (WIERSINGA et al., 2020). E, para poupar os sistemas de saúde de um colapso devido a uma demanda maior que a oferta, o distanciamento social resultou no fechamento do comércio não essencial, áreas de lazer, 


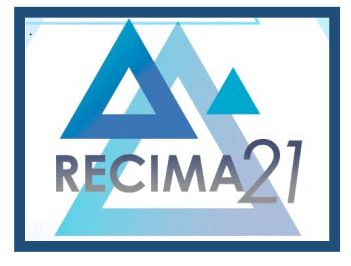

\section{RECIMA21 - REVISTA CIENTÍFICA MULTIDISCIPLINAR ISSN 2675-6218}

escolas (SILVA et al., 2021; BEZERRA et al., 2020; NATIVIDADE et al., 2020) e universidades (BRASIL, 2020)

A crise causada pela COVID-19 afetou mais de $90 \%$ dos estudantes no mundo (UNESCO, 2020) e por conta disso, as atividades acadêmicas e estágios foram suspensos, havendo necessidade de adequação do sistema educacional neste novo contexto (DEDEILIA et al., 2020; GRANJEIRO et al., 2020). As universidades implementaram o ensino remoto emergencial (ERE) com oferta de atividade síncronas e assíncronas, a fim de amenizar tais impactos (VIEIRA et al., 2020; MAGALHÃES et al., 2020).

$\mathrm{Na}$ educação em enfermagem, o desafio se tornou ainda maior, haja vista a necessidade de formar, com urgência, novos profissionais para o enfrentamento da pandemia, dada a carência global por enfermeiros (SILVA et al., 2020). Com isso, utilizou-se de acessibilidade, tecnologias da Informação e Comunicação (TICs) (SANTOS et al., 2021; GOMES et al., 2020), inúmeras plataformas e aplicativos para a continuidade dos estudos (AL-BALAS et al., 2020; SINGH; MASANGO, 2020). A implementação das TICs disponibilizou velocidade no processo de comunicação, transmissão e compartilhamento de informações (CARMO et al., 2020; ABIGAIL, 2021; SILVA et al., 2019).

$\mathrm{Na}$ educação em enfermagem, o desafio foi ainda maior, haja vista a necessidade de formar novos profissionais para o enfrentamento da pandemia de forma imediata, dada a carência global por enfermeiros (SILVA et al., 2020). A implementação das TICs foi positiva, pois disponibilizou velocidade no processo de comunicação, transmissão e compartilhamento de informações (CARMO et al., 2020; ABIGAIL, 2021; SILVA et al., 2019). Entretanto, a mudança instantânea do ensino tradicional (STUART et al., 2012) para o ERE exibiu pouca familiaridade aos recursos tecnológicos entre acadêmicos e docentes (RIES et al., 2020).

É válido destacar que as IESs públicas e privadas mostraram tempos de respostas diferentes às recomendações do Ministério da Educação (MEC), (BRASIL, 2020). As privadas já dispunham de Ambiente Virtual de Aprendizagem (AVA) e TICs mais acessíveis aos acadêmicos pelo histórico de estudo semipresencial (COLETTO et al., 2018; BRASIL, 2004).

Diante deste cenário, levantou-se a seguinte questão: Qual o impacto do ensino remoto na educação superior de Enfermagem no Estado do Pará no contexto da pandemia da Covid-19, na perspectiva dos estudantes? Para tanto, o objetivo do estudo é analisar o ensino remoto na educação superior de Enfermagem no Estado do Pará no contexto da pandemia da Covid-19, na perspectiva dos estudantes.

\section{METODOLOGIA}

Desenho, local de estudo e período

Trata-se de estudo descritivo exploratório, do tipo survey, de abordagem quantitativa. Neste tipo de pesquisa devem-se definir uma amostra e um plano de amostragem para que os resultados 


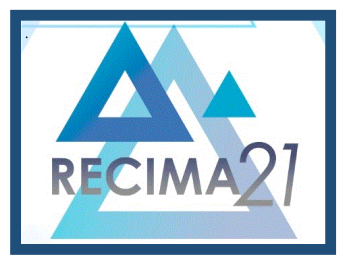

\section{RECIMA21 - REVISTA CIENTÍFICA MULTIDISCIPLINAR ISSN 2675-6218}

sejam sólidos e confiáveis e o desenho da amostra deve representar a população que está sendo analisada e estudada (SILVA et al., 2019). A coleta de dados foi realizada no período de setembro a dezembro de 2020, no Brasil.

População ou amostra

A população foi composta por 10.869 acadêmicos matriculados em cursos de graduação em Enfermagem (presencial e a distância) de instituições de ensino superior (IES) do Pará no ano de 2017 (BRASIL, 2017). Realizou-se amostragem aleatória simples, adotando-se como frequência esperada $50 \%$, margem de erro aceitável de $5 \%$. Para o número amostral foram considerados como limite mínimo para coleta o nível de confiança de 90\%, resultando em 264 participantes, e como limite máximo o nível de confiança de $95 \%$, com 371 . O cálculo amostral foi realizado no programa Statistic Package for Social Sciences (SPSS) versão 24.0.

Foram convidados a participar da pesquisa todos aqueles que preenchessem os critérios de inclusão: ser brasileiro, estudante de graduação em enfermagem regularmente matriculado em uma IES no Estado do Pará, ter acima de 18 anos e ter acesso à internet para responder o questionário. Alternativamente, o critério de exclusão foi a não completude de $90 \%$ das respostas.

\section{Protocolo do estudo}

Para recrutamento de participantes utilizou-se da técnica Bola de Neve (DUSEK et al., 2015), que é uma amostragem não probabilística, e o link do questionário online foi compartilhado nas redes sociais (Facebook, Instagram, WhatsApp) e e-mail. O contato preliminar ocorreu via mensagens eletrônicas, sendo encaminhado um convite formal para a participação, com os objetivos do estudo. $\mathrm{E}$, após o aceite e anuência ao TCLE eletrônico, enviou-se o link do survey (questionário online) para acesso à plataforma Google Forms.

Instrumento de coleta de dados

Diante da inexistência de instrumentos validados para o objetivo do estudo, um questionário online (survey) foi criado pelos pesquisadores, com 24 questões referentes a três domínios: (i) caracterização dos participantes; (ii) avaliação do acesso à Internet e (iii) o ensino-aprendizagem em Enfermagem durante a pandemia. As perguntas foram de múltipla escolha, algumas delas permitindo mais de uma resposta.

O processo de validação de conteúdo do questionário ocorreu em julho de 2020 por seis enfermeiros, docentes de IES pública e privada, no Pará. O questionário foi enviado por e-mail e cada item foi avaliado quanto à apresentação, à clareza, extensão dos anunciados e ao tempo de respostas, e julgados como concordo, discordo e com sugestões. Não foi realizada inferência estatística na análise de conteúdo e as modificações foram ajustadas ao questionário antes da sua veiculação. 


\section{RECIMA21 - REVISTA CIENTÍFICA MULTIDISCIPLINAR ISSN 2675-6218}

ENSINO SUPERIOR EM ENFERMAGEM EM TEMPOS DE PANDEMIA DA COVID-19 Jhonata Correa, Sarah Lais Rocha, Renata Campos de Sousa Borges, Adams Brunno Silva, Mariana Souza de Lima, Gleiciane Moraes Gonçalves, Cintia Yolette Urbano Pauxis Aben-Athar Valentim, Geyse Aline Rodrigues Dias, Gleivison Cunha Teles, Aline Maria Pereira Cruz Ramos, Maicon de Araujo Nogueira

O teste piloto foi realizado com dez voluntários elegíveis ao estudo via online, porém tais dados não foram inclusos nos resultados. O preenchimento total do questionário teve duração média de 20 minutos. Este estudo não foi submetido à avaliação do Comitê de Ética em Pesquisa, pois se caracteriza como pesquisa de opinião pública e voluntária, conforme a Resolução $n^{\circ} 510$, de 7 de abril de 2016 (BRASIL, 2016). Os respondentes foram identificados pelo número cardinal conforme a ordem de envio do instrumento preenchido na plataforma.

Análise dos dados

Os dados coletados foram tabulados, interpretados, processados e analisados por meio da estatística descritiva e inferencial. O teste do Qui-Quadrado foi usado para amostras independentes a fim de testar a hipótese principal: o impacto causado pela pandemia depende do tipo de instituição do acadêmico, privada ou pública; enquanto a hipótese secundária era: os grupos não diferem significativamente. Adotou-se um nível de significância de p-valor $<0.05$.

Foram utilizados os programas Microsoft Excel, Statistic Package for Social Sciences (SPSS) versão 24.0 , todos em ambiente Windows 7.

\section{RESULTADO}

\section{Caracterização dos participantes}

A maioria dos acadêmicos possuía idade entre 20 e 29 anos (202; 67,3\%); não apresentava deficiência (297; 99\%), era solteira $(221 ; 73,7 \%)$, parda $(179 ; 59,7 \%)$, do sexo feminino $(230 ; 76,7 \%)$, residia na região urbana $(295 ; 98,3 \%)$, tinha renda familiar de um a três salários-mínimos (143; $47.7 \%$ ) e não estava trabalhando (202; 67,3\%), como mostrado na Tabela 1. 


\section{RECIMA21 - REVISTA CIENTÍFICA MULTIDISCIPLINAR ISSN 2675-6218}

ENSINO SUPERIOR EM ENFERMAGEM EM TEMPOS DE PANDEMIA DA COVID-19 ata Correa, Sarah Lais Rocha, Renata Campos de Sousa Borges, Adams Brunno Silva, Mariana Souza de Lima, Gleiciane Moraes Gonçalves, Cintia Yolette Urbano Pauxis Aben-Athar Valentim, Geyse Aline Rodrigues Dias, Gleivison Cunha Teles, Aline Maria Pereira Cruz Ramos, Maicon de Araujo Nogueira

Tabela 1: Características sociodemográficas dos acadêmicos de enfermagem em duas IES. ( $\mathrm{n} x$ ) Belém/Estado do Pará, Brasil, 2021.

\begin{tabular}{|c|c|c|c|c|}
\hline \multicolumn{2}{|r|}{ Características Sociodemográficas } & $\mathbf{N}$ & \multirow{2}{*}{$\begin{array}{l}\% \\
67.3 \%\end{array}$} & P-Valor ${ }^{(1)}$ \\
\hline \multirow{5}{*}{ Faixa etária } & $20-29$ anos & 202 & & $0,000^{*}$ \\
\hline & $30-39$ anos & 53 & $17.7 \%$ & \\
\hline & $40-49$ anos & 18 & $6.0 \%$ & \\
\hline & $50-59$ anos & 6 & $2.0 \%$ & \\
\hline & Até 19 anos & 21 & $7.0 \%$ & \\
\hline \multirow{4}{*}{ Estado civil } & Casado(a) & 50 & $16.7 \%$ & $0,000^{*}$ \\
\hline & Divorciado (a) & 3 & $1.0 \%$ & \\
\hline & Solteiro(a) & 221 & $73.7 \%$ & \\
\hline & União Estável & 26 & $8.7 \%$ & \\
\hline \multirow{5}{*}{$\begin{array}{c}\text { Raça/Cor } \\
\text { autodeclarada }\end{array}$} & Amarela & 10 & $3.3 \%$ & $0,000^{*}$ \\
\hline & Branca & 72 & $24.0 \%$ & \\
\hline & Indígena & 3 & $1.0 \%$ & \\
\hline & Negra & 36 & $12.0 \%$ & \\
\hline & Parda & 179 & $59.7 \%$ & \\
\hline \multirow{3}{*}{$\begin{array}{l}\text { Identidade de } \\
\text { gênero }\end{array}$} & Homem & 61 & $20.3 \%$ & $0,000^{*}$ \\
\hline & LGBTQI+ & 9 & $3.0 \%$ & \\
\hline & Mulher & 230 & $76.7 \%$ & \\
\hline \multirow{6}{*}{$\begin{array}{l}\text { Renda } \\
\text { familiar }\end{array}$} & Acima de 9 salários-mínimos & 6 & $2.0 \%$ & $0,000^{*}$ \\
\hline & Até 1 salários mínimos & 78 & $26.0 \%$ & \\
\hline & De 1 a 3 salários mínimos & 143 & $47.7 \%$ & \\
\hline & De 3 a 6 salários mínimos & 51 & $17.0 \%$ & \\
\hline & De 6 a 9 salários mínimos & 15 & $5.0 \%$ & \\
\hline & Nenhuma renda & 7 & $2.3 \%$ & \\
\hline \multirow{3}{*}{ Deficiência } & Não & 297 & $99.0 \%$ & $0,000^{*}$ \\
\hline & Outras deficiências não listadas & 1 & $0.3 \%$ & \\
\hline & Sim, sou pessoa com deficiência auditiva & 2 & $0.7 \%$ & \\
\hline \multirow{2}{*}{ Residência } & Zona Rural & 5 & $1.7 \%$ & $0,000^{*}$ \\
\hline & Zona Urbana & 295 & $98.3 \%$ & \\
\hline \multirow{3}{*}{ Trabalho } & Fui demitido por causa da pandemia & 5 & $1.7 \%$ & $0,000^{*}$ \\
\hline & Não & 202 & $67.3 \%$ & \\
\hline & Sim & 93 & $31.0 \%$ & \\
\hline
\end{tabular}

Fonte: Protocolo de pesquisa (2021).

Nota: ${ }^{(1)}$ Teste Qui-Quadrado (Wilks' $G^{2}$ ) de Pearson para tendência ( $p$-valor<0.05).

*Valores Significativos; NS - Valores Não Significativos.

\section{Condições de acessibilidade pelos participantes}

A Tabela 2 mostra que o acesso à Internet de qualidade foi maior entre acadêmicos de IES privada $(p=0,022)$ e não houve significância em relação às demais variáveis, a maioria classificou a Internet como razoável, acessada principalmente pelo celular. Identificou-se também que os principais locais de acesso à Internet eram residenciais e da IES, e que foi necessária a contratação desse serviço para o ensino remoto emergencial. 


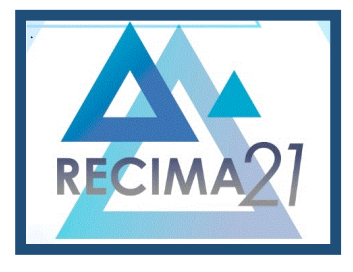

\section{RECIMA21 - REVISTA CIENTÍFICA MULTIDISCIPLINAR ISSN 2675-6218}

Tabela 2: Distribuição dos acadêmicos de enfermagem IES privadas e públicas no Estado do Pará, segundo a acessibilidade à Internet. Belém/Pará. 2021.

\begin{tabular}{|c|c|c|c|c|c|c|}
\hline \multicolumn{6}{|c|}{ IFS Privada } & \\
\hline & & $\mathbf{n}$ & $\%$ & $\mathbf{n}$ & $\%$ & \\
\hline \multirow{5}{*}{ Acesso à Internet } & Utilizo Internet por banda larga cabeada & 43 & $18.2 \%$ & 23 & $35.9 \%$ & 0,022 \\
\hline & Utilizo Internet por banda larga com fibra ótica & 88 & $37.3 \%$ & 23 & $35.9 \%$ & \\
\hline & Utilizo Internet via rádio & 9 & $3.8 \%$ & 2 & $3.1 \%$ & \\
\hline & $\begin{array}{l}\text { Utilizo o acesso via } 3 G \text { ou } 4 G \text { com dados } \\
\text { ilimitados }\end{array}$ & 24 & $10.2 \%$ & 2 & $3.1 \%$ & \\
\hline & $\begin{array}{l}\text { Utilizo o acesso via } 3 G \text { ou } 4 G \text { com limitação } \\
\text { de dados }\end{array}$ & 72 & $30.5 \%$ & 14 & $21.9 \%$ & \\
\hline \multirow{5}{*}{$\begin{array}{l}\text { Qualidade da } \\
\text { conexão }\end{array}$} & Boa & 75 & $31.8 \%$ & 27 & $42.2 \%$ & 0,177 \\
\hline & Muito Boa & 24 & $10.2 \%$ & 3 & $4.7 \%$ & \\
\hline & Péssima & 11 & $4.7 \%$ & 0 & $0.0 \%$ & \\
\hline & Razoável & 98 & $41.5 \%$ & 27 & $42.2 \%$ & \\
\hline & Ruim & 28 & $11.9 \%$ & 7 & $10.9 \%$ & \\
\hline \multirow{4}{*}{$\begin{array}{l}\text { Dispositivo de } \\
\text { acesso à Internet }\end{array}$} & Celular & 172 & $72.9 \%$ & 49 & $76.6 \%$ & $0,714^{\mathrm{b}, \mathrm{c}}$ \\
\hline & Computador de mesa & 2 & $0.8 \%$ & 1 & $1.6 \%$ & \\
\hline & Notebook & 59 & $25.0 \%$ & 14 & $21.9 \%$ & \\
\hline & Tablet & 3 & $1.3 \%$ & 0 & $0.0 \%$ & \\
\hline \multirow{7}{*}{$\begin{array}{c}\text { Acesso à Internet } \\
\text { antes do isolamento } \\
\text { social }\end{array}$} & Casa & 156 & $66.1 \%$ & 44 & $68.8 \%$ & $0,397^{\mathrm{ns}}$ \\
\hline & Casa de amigos ou parentes & 13 & $5.5 \%$ & 2 & $3.1 \%$ & \\
\hline & Casa do namorado & 2 & $0.8 \%$ & 0 & $0.0 \%$ & \\
\hline & Cyber & 0 & $0.0 \%$ & 1 & $1.6 \%$ & \\
\hline & Locais públicos e redes públicas & 1 & $0.4 \%$ & 0 & $0.0 \%$ & \\
\hline & No trabalho & 4 & $1.7 \%$ & 0 & $0.0 \%$ & \\
\hline & Universidade & 60 & $25.4 \%$ & 17 & $26.6 \%$ & \\
\hline \multirow{6}{*}{$\begin{array}{c}\text { Acesso à Internet } \\
\text { durante o isolamento } \\
\text { social? }\end{array}$} & Casa & 222 & $94.1 \%$ & 62 & $96.9 \%$ & $0,891^{\text {ns }}$ \\
\hline & Casa da vizinha & 1 & $0.4 \%$ & 0 & $0.0 \%$ & \\
\hline & Casa de amigos ou parentes & 8 & $3.4 \%$ & 2 & $3.1 \%$ & \\
\hline & Celular & 2 & $0.8 \%$ & 0 & $0.0 \%$ & \\
\hline & Locais públicos e redes públicas & 1 & $0.4 \%$ & 0 & $0.0 \%$ & \\
\hline & Trabalho & 2 & $0.8 \%$ & 0 & $0.0 \%$ & \\
\hline \multirow{2}{*}{$\begin{array}{l}\text { Contratou Internet } \\
\text { durante a pandemia }\end{array}$} & Não & 128 & $54.2 \%$ & 41 & $64.1 \%$ & $0,160^{\text {ns }}$ \\
\hline & Sim & 108 & $45.8 \%$ & 23 & $35.9 \%$ & \\
\hline
\end{tabular}

Fonte: Protocolo de pesquisa (2021).

Nota:

(1) Teste Qui-Quadrado (Wilks' ${ }^{2}$ ) de Pearson para independência ( $p$-valor<0.05).

*Valores Significativos; NS - Valores Não Significativos.

Antes da pandemia, a maioria dos acadêmicos cursava o ensino presencial com tímida integração de tecnologias educacionais pelas IES no processo de ensino. Com a implementação do ERE, as IES privadas suspenderam as práticas laboratoriais e estágios enquanto as IES públicas avaliaram as condições de acesso à Internet entre os acadêmicos $(p=0,001)$.

A substituição do ensino presencial pelo ERE foi avaliada pelos acadêmicos como ruim, com destaque para aqueles de IES privadas $(p=<0,001)$, e $o$ processo de ensino aprendizagem foi mediado por plataforma institucional nas IES privadas e via plataforma Google Suíte nas públicas $(p=0,001)$. As ferramentas digitais aplicadas foram bem aceitas $(p=<0,001)$ nos dois grupos. 


\section{RECIMA21 - REVISTA CIENTÍFICA MULTIDISCIPLINAR ISSN 2675-6218}

Quanto à aprendizagem, foi destacado que as atividades síncronas e assíncronas foram proveitosas tanto para estudantes de IES privadas quanto públicas, $(p=<0,001)$. A postura predominante dos estudantes das IES privadas foi assumir a corresponsabilidade por seu aprendizado e executar as atividades básicas e complementares propostas. Alternativamente, os estudantes de IES públicas afirmaram participar como ouvintes das aulas síncronas e cumprir as tarefas escritas $(p=<0,001)$.

A repercussão do ERE na formação de enfermagem foi encarada de forma diferente entre os grupos $(p=0,034)$, sendo positiva para os acadêmicos de IES privadas em relação à continuação das atividades, e negativa para os demais devido ao atraso do curso por não contemplar as atividades práticas de ensino.

Tabela 3: Distribuição dos acadêmicos de enfermagem IES privadas e públicas no Estado do Pará, segundo a avaliação do ensino-aprendizagem durante a pandemia. Belém/Pará. 2021.

\begin{tabular}{|c|c|c|c|c|c|c|}
\hline & & \multicolumn{3}{|c|}{$\begin{array}{l}\text { IES Privada } \\
(\mathrm{n}=236)\end{array}$} & \multicolumn{2}{|c|}{$\begin{array}{l}\text { IES Pública } \\
\quad(n=64)\end{array}$} \\
\hline & & $\mathrm{n}$ & $\%$ & $\mathrm{n}$ & $\%$ & \\
\hline \multirow{3}{*}{$\begin{array}{l}\text { Modalidade de } \\
\text { ensino antes da } \\
\text { pandemia }\end{array}$} & EAD (ensino a distância) & 2 & $0.8 \%$ & 3 & $4.7 \%$ & \multirow[t]{3}{*}{$0,062^{\text {ns }}$} \\
\hline & Ensino Presencial & 230 & $97.5 \%$ & 61 & $95.3 \%$ & \\
\hline & Ensino Semipresencial & 4 & $1.7 \%$ & 0 & $0.0 \%$ & \\
\hline \multirow{5}{*}{$\begin{array}{c}\text { Integração de } \\
\text { tecnologias digitais } \\
\text { ao ensino- } \\
\text { aprendizagem } \\
\text { ANTES da pandemia }\end{array}$} & Não & 56 & $23.7 \%$ & 17 & $26.6 \%$ & \multirow[t]{5}{*}{$0.107^{\mathrm{ns}}$} \\
\hline & Promoviam plenamente & 10 & $4.2 \%$ & 1 & $1.6 \%$ & \\
\hline & Promoviam pouco & 77 & $32.6 \%$ & 29 & $45.3 \%$ & \\
\hline & Promoviam satisfatoriamente & 26 & $11.0 \%$ & 8 & $12.5 \%$ & \\
\hline & Promoviam, mas precisava melhorar & 67 & $28.4 \%$ & 9 & $14.1 \%$ & \\
\hline \multirow{9}{*}{$\begin{array}{l}\text { Durante a pandemia, } \\
\text { a minha instituição de } \\
\text { ensino }\end{array}$} & $\begin{array}{l}\text { Avaliou as condições de acesso à Internet } \\
\text { para o ensino remoto }\end{array}$ & 73 & $30.9 \%$ & 44 & $68.8 \%$ & \multirow{9}{*}{$0.001^{*}$} \\
\hline & $\begin{array}{l}\text { Avaliou o aproveitamento e/ou aprendizagem } \\
\text { das atividades acadêmicas que foram } \\
\text { ministradas }\end{array}$ & 74 & $31.4 \%$ & 13 & $20.3 \%$ & \\
\hline & $\begin{array}{l}\text { Mapeou os conteúdos e componentes } \\
\text { prioritários para a forma online (ERE) }\end{array}$ & 54 & $22.9 \%$ & 30 & $46.9 \%$ & \\
\hline & Ministrou as práticas em laboratório e estágios & 20 & $8.5 \%$ & 5 & $7.8 \%$ & \\
\hline & $\begin{array}{l}\text { que deveriam ser presenciais por ensino } \\
\text { remoto }\end{array}$ & & & & & \\
\hline & $\begin{array}{l}\text { Não avaliou as condições de acesso à Internet } \\
\text { para o ensino remoto }\end{array}$ & 133 & $56.4 \%$ & 13 & $20.3 \%$ & \\
\hline & $\begin{array}{l}\text { Não avaliou o aproveitamento e/ou } \\
\text { aprendizagem das atividades acadêmicas que } \\
\text { foram ministradas }\end{array}$ & 71 & $30.1 \%$ & 21 & $32.8 \%$ & \\
\hline & $\begin{array}{l}\text { Não mapeou os conteúdos e componentes } \\
\text { prioritários para a forma online }\end{array}$ & 57 & $24.2 \%$ & 17 & $26.6 \%$ & \\
\hline & $\begin{array}{l}\text { Suspendeu e adiou as práticas em laboratório } \\
\text { e estágios, ministrando apenas o conteúdo } \\
\text { teórico }\end{array}$ & 176 & $74.6 \%$ & 35 & $54.7 \%$ & \\
\hline Avaliação da & Bom & 41 & $17.4 \%$ & 6 & $9.4 \%$ & \multirow{4}{*}{$<0,000^{*}$} \\
\hline substituição do & Excelente & 14 & $5.9 \%$ & 0 & $0.0 \%$ & \\
\hline ensino presencial & Não tive ensino remoto & 0 & $0.0 \%$ & 14 & $21.9 \%$ & \\
\hline pelo ERE & Regular & 88 & $37.3 \%$ & 21 & $32.8 \%$ & \\
\hline
\end{tabular}




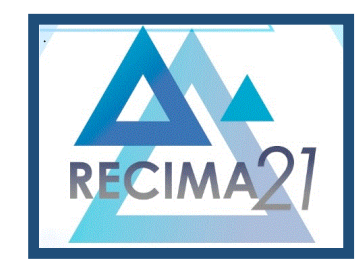

\section{RECIMA21 - REVISTA CIENTÍFICA MULTIDISCIPLINAR ISSN 2675-6218}

ENSINO SUPERIOR EM ENFERMAGEM EM TEMPOS DE PANDEMIA DA COVID-19 ata Correa, Sarah Lais Rocha, Renata Campos de Sousa Borges, Adams Brunno Silva, Mariana Souza de Lima, Gleiciane Moraes Gonçalves, Cintia Yolette Urbano Pauxis Aben-Athar Valentim, Geyse Aline Rodrigues Dias, Gleivison Cunha Teles, Aline Maria Pereira Cruz Ramos, Maicon de Araujo Nogueira

\begin{tabular}{|c|c|c|c|c|c|c|}
\hline & Ruim & 93 & $39.4 \%$ & 23 & $35.9 \%$ & \\
\hline \multirow{4}{*}{$\begin{array}{l}\text { Rotina de estudo } \\
\text { após o isolamento } \\
\text { social }\end{array}$} & $\begin{array}{l}\text { Estou estudando, embora tenha dificuldade de } \\
\text { acompanhar }\end{array}$ & 144 & $61.0 \%$ & 21 & $32.8 \%$ & \multirow{4}{*}{$<0,000^{*}$} \\
\hline & $\begin{array}{l}\text { Estou estudando, exclusivamente, por Ensino } \\
\text { Remoto Emergencial (ERE) }\end{array}$ & 83 & $35.2 \%$ & 25 & $39.1 \%$ & \\
\hline & Não estou estudando & 6 & $2.5 \%$ & 18 & $28.1 \%$ & \\
\hline & Tranquei o curso & 3 & $1.3 \%$ & 0 & $0.0 \%$ & \\
\hline \multirow{5}{*}{$\begin{array}{l}\text { Ferramentas digitais } \\
\text { no processo ensino- } \\
\text { aprendizagem no } \\
\text { ERE }\end{array}$} & Não estou em Ensino Remoto Emergencial & 2 & $0.8 \%$ & 9 & $14.1 \%$ & \multirow[t]{5}{*}{$<0,000$} \\
\hline & Não, a instituição não oferta & 14 & $5.9 \%$ & 11 & $17.2 \%$ & \\
\hline & $\begin{array}{l}\text { Sim, a instituição oferta, mas não tenho } \\
\text { condições de suporte técnico }\end{array}$ & 44 & $18.6 \%$ & 4 & $6.3 \%$ & \\
\hline & $\begin{array}{l}\text { Sim, a instituição oferta, mas tenho } \\
\text { conhecimento limitado }\end{array}$ & 44 & $18.6 \%$ & 11 & $17.2 \%$ & \\
\hline & Sim, consigo acompanhar as atividades & 132 & $55.9 \%$ & 29 & $45.3 \%$ & \\
\hline \multirow{11}{*}{$\begin{array}{l}\text { Quais tecnologias } \\
\text { digitais de } \\
\text { informação têm sido } \\
\text { usadas pela } \\
\text { instituição? }\end{array}$} & Ambiente Virtual de Aprendizagem do Moodle & 18 & $7.6 \%$ & 5 & $7.8 \%$ & \multirow{11}{*}{$0.001^{*}$} \\
\hline & $\begin{array}{l}\text { App de Mensagem Instantânea: Telegram, } \\
\text { WhatsApp, Viber, Skype, etc. }\end{array}$ & 60 & $25.4 \%$ & 30 & $46.9 \%$ & \\
\hline & AVA & 1 & $0.4 \%$ & 0 & $0.0 \%$ & \\
\hline & $\begin{array}{l}\text { Ferramentas digitais do Google Suíte (E-mail, } \\
\text { Meet, Hangouts, Classroom, Forms, Chat) }\end{array}$ & 111 & $47.0 \%$ & 54 & $84.4 \%$ & \\
\hline & Ferramentas digitais do Microsoft Teams & 101 & $42.8 \%$ & 8 & $12.5 \%$ & \\
\hline & $\begin{array}{l}\text { (Chat, videoconterencla, integraçao com } \\
\text { MSOffice) }\end{array}$ & 1 & $0.4 \%$ & 6 & $9.4 \%$ & \\
\hline & Nenhuma & 67 & $28.4 \%$ & 6 & $9.4 \%$ & \\
\hline & Plataforma de Vídeoconferência do Zoom & 150 & $63.6 \%$ & 14 & $21.9 \%$ & \\
\hline & Plataforma virtual da instituição & 15 & $6.4 \%$ & 11 & $17.2 \%$ & \\
\hline & $\begin{array}{l}\text { Recursos digitais: Quizes, Games, } \\
\text { infográficos, podcasts, simulações digitais }\end{array}$ & 19 & $8.1 \%$ & 6 & $9.4 \%$ & \\
\hline & $\begin{array}{l}\text { Redes sociais: Facebook/Instagram/Twitter } \\
\text { Streaming: Netflix, Youtube, Spotify }\end{array}$ & 10 & $4.2 \%$ & 2 & $3.1 \%$ & \\
\hline \multirow{4}{*}{$\begin{array}{l}\text { Autoavaliação no } \\
\text { ERE }\end{array}$} & $\begin{array}{l}\text { Apto à aprendizagem apenas quando o } \\
\text { ofertado o plantão de dúvidas }\end{array}$ & 10 & $4.2 \%$ & 2 & $3.1 \%$ & \multirow{4}{*}{$0,000^{*}$} \\
\hline & $\begin{array}{l}\text { Apto à aprendizagem assíncrona pelo material } \\
\text { de apoio para estudo disponibilizado pelo } \\
\text { docente na plataforma da instituição }\end{array}$ & 105 & $44.5 \%$ & 27 & $42.2 \%$ & \\
\hline & Apto apenas após a aprendizagem síncrona & 114 & $48.3 \%$ & 21 & $32.8 \%$ & \\
\hline & Não estou em Ensino Remoto Emergencial & 7 & $3.0 \%$ & 14 & $21.9 \%$ & \\
\hline \multirow{7}{*}{$\begin{array}{l}\text { Qual tem sido a sua } \\
\text { postura } \\
\text { predominante como } \\
\text { estudante durante o } \\
\text { ensino remoto? }\end{array}$} & $\begin{array}{l}\text { Desenvolvo todas as atividades assíncronas } \\
\text { das disciplinas remotas, inclusive as } \\
\text { complementares }\end{array}$ & 60 & $25.4 \%$ & 14 & $21.9 \%$ & \multirow{7}{*}{$0.024^{*}$} \\
\hline & $\begin{array}{l}\text { Desenvolvo todas as atividades assíncronas } \\
\text { de acordo com o conteúdo básico do plano de } \\
\text { ensino da disciplina }\end{array}$ & 43 & $18.2 \%$ & 16 & $25.0 \%$ & \\
\hline & $\begin{array}{l}\text { Estou acompanhando todas as atividades } \\
\text { propostas e me responsabilizando por parte do }\end{array}$ & 112 & $47.5 \%$ & 26 & $40.6 \%$ & \\
\hline & $\begin{array}{l}\text { meu aprendizado organızando meus estudos } \\
\text { sobre o conteúdo básico e complementar } \\
\text { relativo à disciplina }\end{array}$ & & & & & \\
\hline & $\begin{array}{l}\text { Estou estudando todo o conteúdo produzido e } \\
\text { apresentado pelos professores e conforme as } \\
\text { informações do plano de ensino }\end{array}$ & 86 & $36.4 \%$ & 20 & $31.3 \%$ & \\
\hline & $\begin{array}{l}\text { Nas atividades assíncronas eu estudo sozinho } \\
\text { e às vezes com colegas, quando solicitado } \\
\text { pelo professor }\end{array}$ & 38 & $16.1 \%$ & 10 & $15.6 \%$ & \\
\hline & Nas atividades assíncronas eu estudo sozinho, & 67 & $28.4 \%$ & 25 & $39.1 \%$ & \\
\hline
\end{tabular}




\section{RECIMA21 - REVISTA CIENTÍFICA MULTIDISCIPLINAR ISSN 2675-6218}

ENSINO SUPERIOR EM ENFERMAGEM EM TEMPOS DE PANDEMIA DA COVID-19 nata Correa, Sarah Lais Rocha, Renata Campos de Sousa Borges, Adams Brunno Silva, Mariana Souza de Lima, Gleiciane Moraes Gonçalves, Cintia Yolette Urbano Pauxis Aben-Athar Valentim, Geyse Aline Rodrigues Dias, Gleivison Cunha Teles, Aline Maria Pereira Cruz Ramos, Maicon de Araujo Nogueira

com colegas e por meio de pesquisas na Internet

$\begin{array}{llllll}\text { Participo das atividades síncronas como } 96 & 40.7 \% & 31 & 48.4 \%\end{array}$ ouvinte e cumpro com as tarefas escritas Participo das atividades síncronas ouvindo, $\begin{array}{llllll}\text { fazendo questionamentos, dialogando, } 98 & 41.5 \% & 20 & 31.3 \%\end{array}$ refletindo e cumprindo as tarefas propostas.

Qual a repercussão do ensino remoto para a sua formação em Enfermagem?

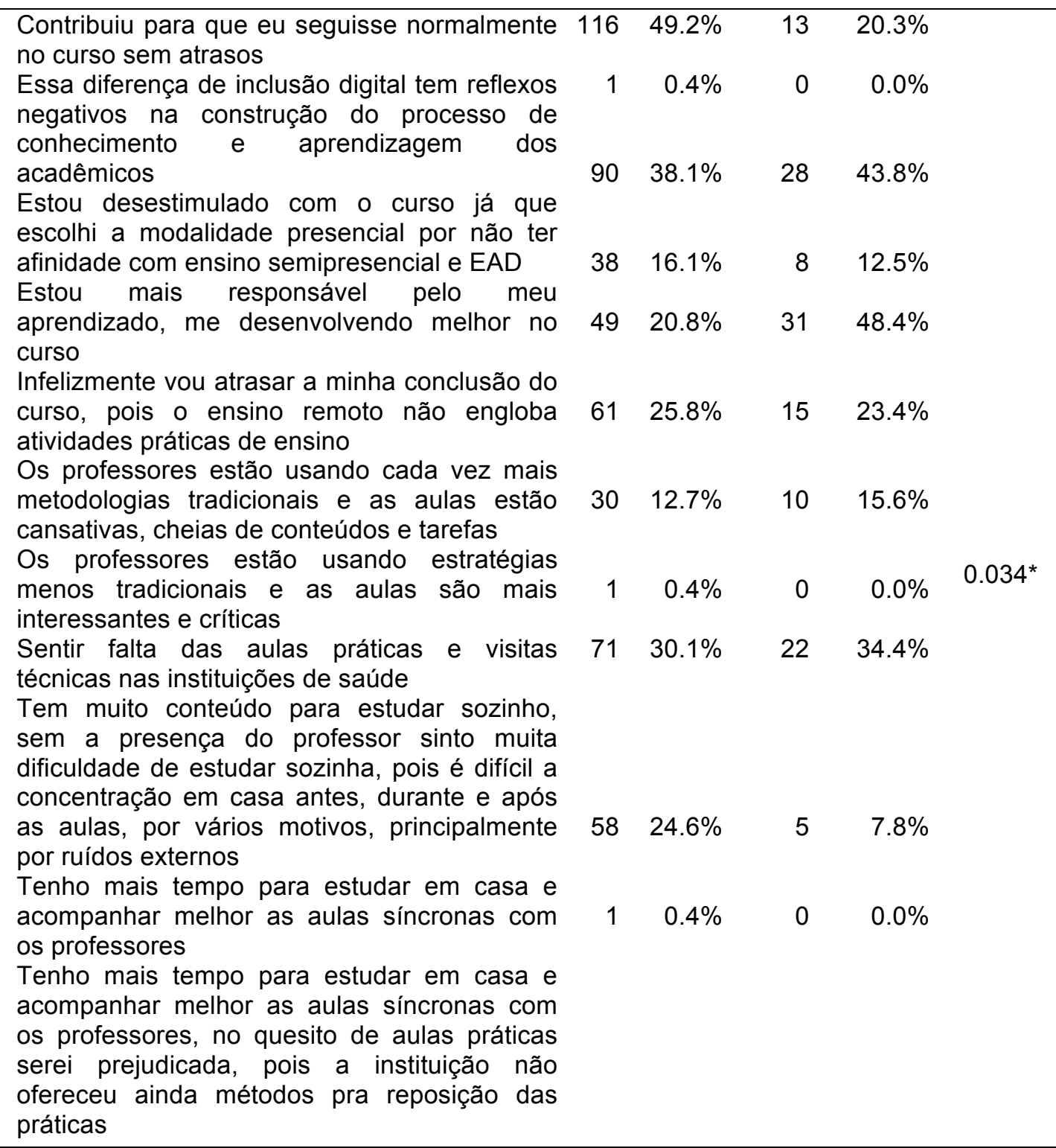

no curso sem atrasos

Essa diferença de inclusão digital tem reflexos negativos na construção do processo de conhecimento e aprendizagem dos acadêmicos

Estou desestimulado com o curso já que escolhi a modalidade presencial por não ter afinidade com ensino semipresencial e EAD curso Os professores estão usando cada vez mais metodologias tradicionais e as aulas estão cansativas, cheias de conteúdos e tarefas

técnicas nas instituições de saúde

Tem muito conteúdo para estudar sozinho, por ruídos externos

Tenho mais tempo para estudar em casa e os professores

Tenho mais tempo para estudar em casa $e$ ofereceu ainda métodos pra reposição das práticas

Fonte: Protocolo de pesquisa (2021).

Nota: ${ }^{(1)}$ Teste Qui-Quadrado (Wilks' $\mathrm{G}^{2}$ ) de Pearson para independência (p-valor<0.05).

*Valores Significativos; NS - Valores Não Significativos.

\section{DISCUSSÃO}

Identificou-se que a maioria dos estudantes era jovem (20 - 29 anos), parda (179; 59,7\%), do sexo feminino $(230 ; 76,7 \%)$, solteira $(221 ; 73,7 \%)$, não apresentava deficiência $(297 ; 99 \%)$ e residia 

ISSN 2675-6218

na região urbana $(295 ; 98,3 \%)$, o que converge com o perfil dos participantes de estudos prévios (CHAVES et al., 2016; RAMOS-MORCILLO et al., 2020). Uma pesquisa que traça o "Perfil da Enfermagem no Brasil" aponta semelhança aos achados desta pesquisa, com relação a sexo e local de residência, já, nos parâmetros faixa etária, estado civil e cor autodeclarada, apresenta singela convergência (FIOCRUZ, 2013). Nenhum estudo avaliou a presença de deficiência entre os estudantes de enfermagem.

Foi evidenciado que a maioria dos participantes cursava graduação em IES privada, dispunha de baixa renda familiar (1 a 3 salários-mínimos) e não trabalhava, dados similares aos resultados de estudos com acadêmicos de enfermagem no estado do Ceará e Piauí (MOURA et al., 2016; NETO et al., 2017). A rede privada é dominante na oferta para educação em enfermagem, quando comparada com a rede pública (VIANNA, 2019). Ademais, é relevante destacar a contribuição do Financiamento Estudantil (FIES) para à expansão do acesso e democratização no ensino superior privado (COSTA et al., 2020).

Relatório da Organização das Nações Unidas para Educação, Ciência e Cultura (Unesco, 2020) estima que em torno de 1,5 bilhão de estudantes em mais de 100 países foi atingido pela paralisação acadêmica durante a pandemia. Para mitigar tal impacto negativo, o Ministério da Educação divulgou a Portaria $n^{\circ} 343$, de 17 de março de 2020, que autorizou a substituição das aulas presenciais pelas remotas (BRASIL, 2020).

No que tange ao ensino superior de enfermagem, torna-se incongruente a aplicação desta modalidade em todo o curso, visto que há um grande risco de ocorrer a formação de profissionais com boa capacidade teórica, porém com mínima capacidade prática/técnica, e, consequentemente, maiores riscos de dano aos pacientes (SCORSOLINI-COMIN et al., 2020).

O ERE tem sido um processo desafiador pela quebra de paradigmas e necessidade de melhoria das habilidades, competências pedagógicas e tecnológicas daqueles envolvidos no processo de ensino-aprendizagem (BASTOS et al., 2020; SOY-MUNER, 2020). Além disso, o ERE traz consigo o protagonismo dos estudantes devido à autogestão de tempo, autodisciplina, método de estudo e motivação (THEORET \& MIG, 2020).

Observou-se, neste estudo, que o acesso à Internet de qualidade (fibra ótica ou cabo) foi maior nos dois grupos, sendo observado ainda o uso significativo do acesso via $3 G$ ou 4G com limitação de dados móveis naqueles da IES privada $(p=0,022)$, o que poderia ser um fator limitador ao processo de ensino-aprendizagem (OLUM et al., 2020), uma vez que a Internet é essencial no contexto pandêmico para execução do ERE. Em um estudo com 27.827 estudantes de uma instituição pública que demonstram fragilidade de acesso à Internet no Pará, 9.052 (32,5\%) não possuíam meios de acesso à Internet em todo o estado (GOMES et al., 2021). Visto isso, é importante destacar que o Estado do Pará possui 63,3\% de seus municípios classificados na faixa de muito alta vulnerabilidade social (PARÁ, 2015). 


\section{RECIMA21 - REVISTA CIENTÍFICA MULTIDISCIPLINAR ISSN 2675-6218}

Conforme dados extraídos do sítio oficial da Agência Nacional de Telecomunicações Anatel, no Pará, em março deste ano, existiam 8,9 milhões de contratos de telecomunicações ativos, com uma densidade de acesso de 22,1 para cada 100 domicílios. Com relação à tecnologia banda larga, 58,2\% eram de fibra ótica; 21,4 , cabo axial; 9,2, rádio; 3,3, satélite; e 7,9, cabo metálico. Já, com relação à Tecnologia Telemóvel (4G, 3G e 2G), 81,4\% tinham acesso à cobertura 4G; 8,5\%, a 3G; e 10,5\%, a 2G (BRASIL, 2021).

A acessibilidade à Internet de qualidade (banda larga) cresceu de $82,9 \%$ para $84,2 \%$ entre os anos de 2017 e 2018, no Brasil (BRASIL, 2018), embora uma pesquisa com acadêmicos de enfermagem apontasse a avaliação de acesso à Internet como boa a razoável (OLUM et al., 2020).

Além da Internet, destaca-se a relevância das Tecnologias Digitais de Comunicação e Informação (TDCl) como ferramentas importantes para que o ERE seja desenvolvido. Há uma variedade delas e podem ser aplicadas conforme o objetivo planejado. O seu principal objetivo é promover o compartilhamento de informações através de computadores, Internet e redes sociais para desencadear alterações significantes na aprendizagem ativa, pois há maior participação e colaboração entre os pares (ALVES et al., 2020; FRANZOI et al., 2018). Na enfermagem, tendem a oferecer estratégias inovadoras de ensino-aprendizagem (SINGH; MASANGO, 2020), além de incitar a prática baseada em evidências (HARERIMANA et al., 2020).

Cerca de 59 (25\%) e 172 (72.9\%) utilizam notebook e celular como principal dispositivo de acesso à internet, respectivamente, semelhante a estudo anterior (ABBASI et al., 2020). Logo, é importante salientar que, o uso dessas novas estratégias pedagógicas trouxe desafios não apenas para lidar com a tecnologia, mas também para a adaptação dos estudantes no que diz respeito à saúde mental no lar e manejo do tempo para estudo (RAJAB; GAZAL \& ALKATTAN, 2020). Ademais, sem escolas, as famílias cuidam integralmente das crianças; com o teletrabalho, devem dividir os equipamentos de estudo, como o computador, e os ambientes para tal com os outros membros (SILVA et al., 2020).

No que tange às variáveis "Qual o local principal de acesso à internet ANTES do isolamento social?", não se encontraram estudos referentes.

Durante o isolamento social, $156(66.1 \%)$ relataram usar a Internet principalmente em casa, assemelhando-se ao estudo de Neupane et al. (2020), no qual $88.8 \%$ tinham acesso à Internet em domicílio. Dos participantes, $108(45.8 \%)$ precisaram contratar Internet durante a pandemia para se adequar ao ensino remoto, em consonância com estudo nas Filipinas, onde $79 \%$ contrataram um serviço de Internet pós-pago (BATICULON et al., 2021). Todavia, o impacto da pandemia no setor econômico corrobora para que alguns estudantes careçam de acesso à Internet, em decorrência de dificuldades financeiras (CARDOSO et al., 2020).

No que tange à modalidade de ensino antes da pandemia, $230(97.5 \%)$ responderam cursar por ensino presencial. Este resultado era esperado, pois cerca de 1.180 instituições de nível superior ofertam curso de graduação em Enfermagem, das quais 1.172 na modalidade presencial e oito na 


\section{RECIMA21 - REVISTA CIENTÍFICA MULTIDISCIPLINAR} ISSN 2675-6218

modalidade de Ensino a Distância (LIRA et al., 2020), respaldada pelo Decreto $n^{\circ} 9.057$, de 25 de maio de 2017, que em seu artigo $2^{\circ}$ estabelece essa modalidade de ensino (BRASIL, 2017). Porém, devido à mudança para o ERE, docentes e estudantes precisaram se adaptar à nova sala de aula, criar novas rotinas e conciliar espaços em casa (BEZERRA et al., 2020), tornando esse novo método menos atraente, exigindo mudanças relevantes na metodologia docente (VALENTE et al., 2020).

Segundo 67 (28.4\%) estudantes, a instituição poderia melhorar o uso de tecnologias digitais no ensino antes da pandemia, pois ainda é limitado o uso de tecnologias tanto por parte das instituições educativas quanto pelos professores (SILVA et al., 2018). Além disso, os docentes não possuem afinidade e expertise para aplicar as ferramentas tecnológicas no ensino-aprendizagem, visto que os mesmos, por vezes, possuem pouca prática de utilização de tecnologias digitais e necessitam de capacitação para que consigam instrumentalizar tais meios na educação (SILVEIRA et al., 2021).

A maioria dos envolvidos, $176(74.6 \%)$, respondeu que sua instituição adiou as práticas em laboratórios e estágios, ministrando apenas conteúdo teórico. Muitos países optaram por aulas online e as práticas clínicas foram canceladas (SINGH et al., 2021), afetando diretamente a formação em enfermagem, a qual exige o estabelecimento de vínculos de confiança, permitindo cuidados e orientações em cenários reais de prática (LIRA et al., 2020). Em suma, há uma grande urgência em formar novos profissionais devido à escassez global de enfermeiros, profissão em que está inserida a prática do cuidado, dificultando a execução de uma educação qualitativa, se realizada apenas a aplicação remota do ensino (SILVA et al., 2021).

Noventa e três (39.4\%) estudantes avaliaram a substituição do ensino presencial pelo remoto como ruim, já que este não lhes proporcionou habilidades de comunicação necessárias para a prática profissional, e que esse método de ensino impactou negativamente em sua aprendizagem (NICKLEN et al., 2016).

Sobre a rotina de estudos após o isolamento social, 144 (61.0\%) relataram estar estudando, embora com dificuldades de acompanhar, em decorrência da não preparação dos estudante para se adaptarem a esse novo ambiente de ensino (GUSSO et al., 2020), além de problemas com Internet, aparelhos eletrônicos e dificuldade de concentração nas atividades (MAGALHÃES et al., 2020), visto que esse tipo de ensino é excludente, somado à burocratização do sistema e à carência de investimentos na educação (MÉLO et al., 2020). Esse processo ativo do ERE torna o estudante condutor do processo de ensino, deixando o papel de sujeito passivo e se tornando sujeito ativo (SILVA et al., 2018).

No que tange à utilização de ferramentas digitais no processo ensino-aprendizagem pelas instituições, 132 (55.9\%) responderam sim e que conseguiam acompanhar as atividades, consoante a estudo em que os sujeitos relataram participar de aulas online e assistir vídeos gravados, apesar de $21 \%$ dos respondentes não terem recebido orientações quanto à aprendizagem online (BECKER et al., 2020). Esse resultado reflete a idade dos participantes, os quais fazem parte da Geração Z, ou 


\section{RECIMA21 - REVISTA CIENTÍFICA MULTIDISCIPLINAR ISSN 2675-6218}

nativos digitais, familiarizados com tecnologias como Wi-Fi, smartphones, tablets, jogos online e serviços virtuais de comunicação (PASSERO et al., 2016).

Sobre as tecnologias digitais de informação usadas no ensino, 111 (47.0\%) relataram usar ferramentas digitais do Google Suíte e 150 (63,6\%) afirmaram usar a plataforma da instituição de ensino, porém, em outro estudo as plataformas Zoom e Google foram as mais utilizadas na aprendizagem online (CAMARGO et al., 2020). Esses ambientes virtuais de aprendizagem (AVAs) são plataformas nas quais o docente pode disponibilizar ferramentas educativas, executar atividades e avaliações, além de manter comunicações com os estudantes (CHIAVONE et al., 2021).

Cerca de 114 (48.3\%) estudantes relataram estarem aptos apenas após aprendizagem síncrona, diferente de outros estudantes que revelaram ter dificuldades em participar de aulas síncronas, sendo aulas gravadas no Youtube escolhidas como melhor formato para acompanhar os estudos (APPENZELLER et al., 2020). Conforme as respostas dos estudantes, 112 (47.5\%) estavam acompanhando todas as atividades e se responsabilizando em parte por seu aprendizado no ensino remoto, visto que eles normalmente tinham mais intimidade com o emprego tecnológico e o mundo digital (SILVEIRA et al., 2021). No estudo de Vatier et al. (2021), o acompanhamento do ensino remoto entre estudantes foi desigual, onde $6 \%$ dos estudantes não acompanharam nenhuma aula, $36 \%$ assistiram menos da metade dos cursos e $21 \%$ usufruíram de todos os recursos disponíveis.

Para 116 (49.2\%) estudantes, o ensino remoto contribuiu para o seguimento normal do curso sem atrasos, todavia, a adoção do ERE em meio à pandemia mostrou que, além de impactos negativos no processo de ensino-aprendizagem pela falta de acessibilidade às tecnologias, o panorama da pandemia trouxe também alterações sócioemocionais e econômicas que influenciam diretamente no ensino e aprendizagem (FERNANDES et al., 2020), somado ao fato de que os docentes utilizam mais metodologias tradicionais, centradas nos mesmos, onde o estudante é tido como ser passivo, pouco crítico e reflexivo (MEDEIROS et al., 2021).

\section{CONSIDERAÇÕES FINAIS}

A pandemia da Covid-19 trouxe impactos em diversas vertentes, assim como na educação do ensino superior em enfermagem. Um processo de ensino-aprendizagem tradicional, presencial e com incorporação tímida de tecnologias e limitada acessibilidade foi relatado antes da pandemia pelos acadêmicos dos dois grupos.

Durante a pandemia, paradigmas foram quebrados pela implementação do ERE, com a necessidade de contratação de Internet de melhor qualidade e maior incorporação de TICs. Isso ecoou na aquisição de habilidades e competências pelos estudantes diante da busca de maior autonomia para a sua rotina de estudos.

Identificou-se ainda que os acadêmicos de IES privadas não foram consultados quanto à acessibilidade à Internet, uma vez que tais instituições apresentavam melhor estrutura digital 


\section{RECIMA21 - REVISTA CIENTÍFICA MULTIDISCIPLINAR ISSN 2675-6218}

institucional. E isso foi identificado, destacando-se uma acessibilidade melhor entre eles, porém, a maior frequência de críticas negativas em relação ao ERE veio desse mesmo grupo.

Um dado interessante foi a divergência da avaliação do ERE em relação à formação profissional, sendo positiva para os acadêmicos da IES privada e negativa para os das públicas, o que reflete objetivos diferentes entre eles diante da finalização do curso e necessidade de prática clínica, respectivamente.

\section{REFERÊNCIAS}

ABBASI, S.; AYOOB, T.; MALIK, A.; MEMON, S. I. Perceptions of students regarding E-learning during Covid-19 at a private medical college. Pak J Med Sci., v. 36 2020. Disponível em: https://www.ncbi.nlm.nih.gov/pmc/articles/PMC7306963/pdf/PJMS-36-S57.pdf. Acesso em: 25 jun. 2021 DOI: https://doi.org/10.12669/pjms.36.COVID19-S4.2766.

ABIGAIL, Alexandra Razo Yugcha. El uso de las TIC en el entrenamiento deportivo: una propuesta operativa ante la COVID-19. Rev Podium, Pinar del Río, v. 16, n. 1, p. 76-87, abr. 2021.

Disponible em: http://scielo.sld.cu/scielo.php?script=sci_arttext\&pid=S199624522021000100076\&lng=es\&nrm=iso. accedido em: 09 jun. 2021.

AL-BALAS, M.; AL-BALAS, H. I.; JABER, H. M.; OBEIDAT, KHALED; AL-BALAS, H.; ABORAJOOH, E.A.; AL-TAHER, Raed; AL-BALAS, Bayan. Distance learning in clinical medical education amid COVID-19 pandemic in Jordan: current situation, challenges, and perspectives. BMC Med Educ, v. 341, 2020. Disponível em: https://bmcmededuc.biomedcentral.com/articles/10.1186/s12909-02002257-4 Acesso em: 25 jun. 2021. DOI: https://doi.org/10.1186/s12909-020-02257-4 .

ALVES, A. G.; CESAR, F. C. R.; MARTINS, C. A.; RIBEIRO, L. C. M.; OLIVEIRA, L. M. A. C.; BARBOSA, M. A.; LIMA, K. M. Tecnologia de informação e comunicação no ensino de enfermagem. Acta Paulista de Enfermagem [online]., v. 33, 2020. Disponível em: https://doi.org/10.37689/actaape/2020A001385

APPENZELLER, Simone; HUSEMANN, Fábio Menezes; GOULART, Gislaine dos Santos; FERREIRA, Roberto Padilha; SABINO, Higor Graça; FRÓES, Joana Bragança. Novos Tempos, Novos Desafios: Estratégias para Equidade de Acesso ao Ensino Remoto Emergencial. Revista Brasileira de Educação Médica [online]., v. 44, n. Suppl 01, 2020. Disponível em: https://doi.org/10.1590/1981-5271v44.supl.1-20200420. Acesso em: 25 jun. 2021

BARBOSA, E. da S.; CHAVES, M. J. C.; TORRES, M. N. B. F.; NÓBREGA-THERRIEN, S. M. O desenho animado como metodologia ativa e lúdica no processo de ensino-aprendizagem em enfermagem. Educação: Teoria e Prática, Rio Claro, v. 28, n. 59, p. 529-547, set./dez. 2018. Disponível em:

https://www.periodicos.rc.biblioteca.unesp.br/index.php/educacao/article/view/12191/8700. Acesso em: 19 jul. 2021.

BASTOS, M. C.; CANAVARRO, D. A.; CAMPOS, L. M.; SCHULZ, R. S.; SANTOS, J. B.; SANTOS, C. F. Ensino remoto emergencial na graduação em Enfermagem: relato de experiência na Covid-19. REME - Rev Min Enferm., v. 24, e-1335, 2020. Disponível em: https://cdn.publisher.gn1.link/reme.org.br/pdf/e1335.pdf. DOI: 10.5935/1415.2762.20200072.

BATICULON, R. E.; SY, J. J.; ALBERTO, N. R. I; BARON, M. B. C.; EARL, R. C. M.; RIZADA, L. G. T.; JAN, C. S. T; CLARION, C. A.; REYES, J. C. B. Barriers to Online Learning in the Time of COVID19: A National Survey of Medical Students in the Philippines. Med. Sci. Educ., v. 31, p. 615-626, 


\section{RECIMA21 - REVISTA CIENTÍFICA MULTIDISCIPLINAR ISSN 2675-6218}

2021. Disponível em: https://link.springer.com/article/10.1007/s40670-021-01231-z DOI: https://doi.org/10.1007/s40670-021-01231-z.

BECKER, S. P.; BREAUX, R.; CUSICK, C. N.; DVORSKY, M. R.; MARSH, N. P.; SCIBERRAS, E.; LANGBERG, J. M. Remote Learning During COVID-19: Examining School Practices, Service Continuation, and Difficulties for Adolescents With and Without Attention-Deficit/Hyperactivity Disorder. J Adolesc Health., v. 67, n. 6, p. 769-777, Dec. 2020. DOI: 10.1016/j.jadohealth.2020.09.002. Disponível em: https://www.jahonline.org/article/S1054139X(20)30523-1/fulltext.

BEZERRA, Anselmo César Vasconcelos et al. Fatores associados ao comportamento da população durante o isolamento social na pandemia de COVID-19. Ciência \& Saúde Coletiva [online], v. 25, suppl 1, p. 2411-2421, 2020. Disponível em: https://doi.org/10.1590/1413-81232020256.1.10792020. ISSN 1678-4561 Acesso em: 23 jun. 2021. DOI: https://doi.org/10.1590/141381232020256.1.10792020.

BEZERRA, K. P.; COSTA, K. F. de L.; OLIVEIRA, L. C. de; FERNANDES, A. C. L.; CARVALHO, F. P. B. de; NELSON, I. C. A. de S. R. Remote teaching in state public universities: the future that is present. Research, Society and Development, [S. I.], v. 9, n. 9, p. e359997226, 2020. DOI: 10.33448/rsd-v9i9.7226. Disponível em: https://rsdjournal.org/index.php/rsd/article/view/7226. Acesso em: 19 jul. 2021.

BRASIL. Agência nacional de telecomunicações. Brasília: Anatel, 2021. Disponível em: https://informacoes.anatel.gov.br/paineis/acessos. Acesso em: 28 jul. 2021.

BRASIL. Decreto $N^{\circ}$ 9.057, de 25 de maio de 2017. Regulamenta o art. 80 da Lei n 9.394, de 20 de dezembro de 1996, que estabelece as diretrizes e bases da educação nacional. Disponível em: https://www.in.gov.br/materia/-/asset_publisher/Kujrw0TZC2Mb/content/id/20238603/do1-2017-05-26decreto-n-9-057-de-25-de-maio-de-2017-20238503. Acesso em: 19 jul. 2021.

BRASIL. Instituto Brasileiro de Geografia e Estatística (IBGE). Pesquisa Nacional por Amostra de Domicílios Contínua: Acesso à Internet e à televisão e posse de telefone móvel celular para uso pessoal 2017. Brasília (DF): IBGE; 2017. Available from: https://biblioteca.ibge.gov.br/visualizacao/livros/liv101631_informativo.pdf. Acesso em: 28 jul. 2021.

BRASIL. Sinopse Estatísticas da Educação Superior - Graduação. Brasília, DF: INEP, 2017. Disponível em: http://inepe.gov.br/web/sinopse-estatisticas-da-educação-superior\&gt. Acesso em: 28 jul. 2020.

BRASIL. PORTARIA N 4.059, DE 10 DE DEZEMBRO DE 2004. Brasília: MINISTÉRIO DA EDUCAÇÃO, 2004. Disponível em: http://portal.mec.gov.br/sesu/arquivos/pdf/port4059-2004.pdf. Acesso em: 28 jul. 2021.

BRASIL. MINISTÉRIO DA SAÚDE. Doença pelo Coronavírus COVID-19. $71^{\circ}$ Boletim Epidemiológico Especial. Semana Epidemiológica 27 (4 a 10 / 7 / 2021). Disponível em: https://www.gov.br/saude/pt-br/media/pdf/2021/julho/16/boletim epidemiologico covid 71.pdf. Acesso em: 04 ago. 2021.

BRASIL. PLENÁRIO DO CONSELHO NACIONAL DE SAÚDE. Resolução № $\mathbf{5 1 0}$, de 07 de abril de 2016. Dispõe sobre as normas aplicáveis a pesquisas em Ciências Humanas e Sociais cujos procedimentos metodológicos envolvam a utilização de dados diretamente obtidos com os participantes ou de informações identificáveis ou que possam acarretar riscos maiores do que os existentes na vida cotidiana. Disponível em: http://conselho.saude.gov.br/resolucoes/2016/Reso510.pdf. 


\section{RECIMA21 - REVISTA CIENTÍFICA MULTIDISCIPLINAR ISSN 2675-6218}

BRASIL. Portaria $\mathbf{N}^{\circ} \mathbf{3 4 3}$, de 17 de março de 2020. Dispõe sobre a substituição das aulas presenciais por aulas em meios digitais enquanto durar a situação de pandemia do novo Coronavírus - covid-19. Disponível em: https://www.in.gov.br/en/web/dou/-/portaria-n-343-de-17-de-marco-de2020-248564376. Acesso em: 28 jul. 2021.

BRASIL. Portaria $\mathbf{N}^{\circ} \mathbf{3 7 4}$, de 3 de abril de 2020. Dispõe sobre a antecipação da colação de grau para os alunos dos cursos de Medicina, Enfermagem, Farmácia e Fisioterapia, exclusivamente para atuação nas ações de combate à pandemia do novo coronavírus - Covid-19. Disponível em: https://www.in.gov.br/en/web/dou/-/portaria-n-374-de-3-de-abril-de-2020-251289249. Acesso em: 09 jun. 2021.

BRASIL. Portaria $\mathbf{N}^{\circ}$ 544, de 16 de junho de 2020. Dispõe sobre a substituição das aulas presenciais por aulas em meios digitais, enquanto durar a situação de pandemia do novo coronavírus - covid-19, e revoga as portarias MEC $n^{\circ} 343$, de 17 de março de 2020, $N^{\circ} 345$, de 19 de março de 2020, e $\mathrm{N}^{\circ}$ 473, de 12 de maio de 2020. Disponível em: https://www.in.gov.br/en/web/dou/-/portaria-n544-de-16-de-junho-de-2020-261924872. Acesso em: 09 jun. 2021.

CAMARGO, C. P.; ZEN, P. T.; FREITAS, F. B.; ARRUDA, M. M.; GEMPERLI, Rolf. Online learning and COVID-19: a meta-synthesis analysis. Clinics [online], v. 75, 2020. ISSN 1980-5322. Available from: https://doi.org/10.6061/clinics/2020/e2286. Accessed 25 June 2021.

CARDOSO, Cristiane Alves; FERREIRA, Valdivina Alves; BARBOSA, Fabiana Carla Gomes. (Des)igualdade de acesso à educação em tempos de pandemia: uma análise do acesso às tecnologias e das alternativas de ensino remoto. Revista Com Censo: Estudos Educacionais do Distrito Federal, [S. I.], v. 7, n. 3, p. 38-46, ago. 2020. ISSN 2359-2494. Disponível em: http://www.periodicos.se.df.gov.br/index.php/comcenso/article/view/929. Acesso em: 19 jul. 2021.

CARMO, J. R. do; PACIULLI, S. de O. D. .; NASCIMENTO, D. L. do . O impacto do uso de Tecnologias de Informação e Comunicação (TIC's) por docentes dos Institutos Federais localizados em Minas Gerais em um contexto de pandemia. Research, Society and Development, [S. I.], v. 9, n. 10, p. e5199108940, 2020. DOI: 10.33448/rsd-v9i10.8940. Disponível em: https://www.rsdjournal.org/index.php/rsd/article/view/8940. Acesso em: 9 jun. 2021.

CHAVES, C. M.; NELAS, P. A.; CRUZ, C. M; COUTINHO, E.; AMARAL, Odete. O perfil sociodemográfico e académico dos estudantes de enfermagem e o bem estar. INFAD Revista de Psicología, v. 2, n. 1, p. 123-132, 2016. ISSN: 0214-9877. Disponível em: https://revista.infad.eu/index.php/IJODAEP/article/view/224/218.

CHIAVONE, F. B. T.; PAIVA, R. M.; MORENO, I. M.; PÉREZ, P. E.; FEIJÃO, A. R.; SANTOS, V. E. P. Tecnologias utilizadas para apoio ao processo de enfermagem: revisão de escopo. Acta Paul Enferm, v. 34, 2021. Disponível em: https://www.scielo.br/j/ape/a/Dm6zGKT5k3Sf58pxS7chCDQ/?format=pdf\&lang=pt. DOI: http://dx.doi.org/10.37689/actaape/2021AR01132.

CHIRELLI, Mara Quaglio Sordi; LEMES, Mara Regina de. Critical thinking in nursing training: evaluation in the area of competence Education in Health. Revista Brasileira de Enfermagem [online], v. 74, suppl 5, 2021. Available from: https://doi.org/10.1590/0034-7167-2020-0979. Accessed 23 June 2021.

COLETTO, P. M. de C.; BATTINI, O.; MONTEIRO, E. Tecnologias da informação e comunicação e as metodologias ativas: elementos para o trabalho docente no ensino superior. Revista Prática Docente, [S. I.], v. 3, n. 2, p. 798-812, 2018. Disponível em: http://periodicos.cfs.ifmt.edu.br/periodicos/index.php/rpd/article/view/281. Acesso em: 28 jul. 2021. DOI: 10.23926/RPD.2526-2149.2018.v3.n2.p798-812.id281. 


\section{RECIMA21 - REVISTA CIENTÍFICA MULTIDISCIPLINAR ISSN 2675-6218}

CONCEIÇÃO, M. G. da; ROCHA, U. R. TIC para manutenção dos estudos em período de pandemia na Universidade Federal da Bahia. Folha de Rosto, v. 6, n. 2, p. 95-106, jul. 2020. Disponível em: https://periodicos.ufca.edu.br/ojs/index.php/folhaderosto/article/view/528/470. Acesso em: 22 jul. 2021.

COSTA, Ivy Silva et al. O impacto de uma Política Pública Educacional no Enade: uma avaliação do FIES. Revista Meta: Avaliação, [S.I.], v. 12, n. 35, p. 437-468, june. 2020. ISSN 2175-2753. Disponível em: https://revistas.cesgranrio.org.br/index.php/metaavaliacao/article/view/2274. Acesso em: 24 june. 2021. DOI: http://dx.doi.org/10.22347/2175-2753v12i35.2274.

DEDEILIA, A.; SOTIROPOULOS, M. G.; HANRAHAN, J. G.; JANGA, D.; DEDEILIAS, P.; SIDERIS, M. Medical and Surgical Education Challenges and Innovations in the COVID-19 Era: A Systematic Review. In Vivo, v. 34, n. 3, Suppl, p. 1603-1611, Jun. 2020. Disponível: https://iv.iiarjournals.org/content/invivo/34/3_suppl/1603.full.pdf. DOI: 10.21873/invivo.11950.

DUARTE, Maria de Lourdes Custódio, SILVA, Daniela Giotti da; BAGATINI, Mariana Mattia Correa. Nursing and mental health: a reflection in the midst of the coronavirus pandemic. Revista Gaúcha de Enfermagem [online], v. 42, n. spe, 2021. Disponível em: https://doi.org/10.1590/19831447.2021.20200140. Acesso em 8 jun. 2021.

DUSEK, G. A.; YUROVA, Y. V.; RUPPEL, C. P. Using social media and targeted snowball sampling to survey a hard-to-reach population: a case study. Int J Doctoral Stud [Internet], 2015. Available from: http://ijds.org/Volume10/IJDSv10p279-299Dusek0717.pdf.

FERNANDES, Ana Paula Campos; ISIDORIO, Allisson Roberto; MOREIRA, Edney Ferreira. Ensino remoto em meio à pandemia do covid-19: panorama do uso de tecnologias. In.: Anais do CIET:EnPED:2020 - (Congresso Internacional de Educação e Tecnologias | Encontro de Pesquisadores em Educação a Distância), São Carlos, ago. 2020. ISSN 2316-8722. Disponível em: https://cietenped.ufscar.br/submissao/index.php/2020/article/view/1757.

FRANZOI, M. A. H.; SILVEIRA, A. O. Tecnologias digitais da informação e comunicação na graduação em Enfermagem: relato de uma atividade pedagógica. REME - Rev Min Enferm, v. 22, p. e-1145, 2018. DOI: 10.5935/1415-2762.20180076.

FUNDAÇÃO OSWALDO CRUZ (FIOCRUZ). Conselho Federal de Enfermagem (COFEn). Perfil da Enfermagem no Brasil: Questionário. Rio de Janeiro: FIOCRUZ, 2013.

GOMES, Vânia Thais Silva et al. A Pandemia da Covid-19: Repercussões do Ensino Remoto na Formação Médica. Revista Brasileira de Educação Médica [online], v. 44, n. 04, 2020. Disponível em: https://doi.org/10.1590/1981-5271v44.4-20200258. Acesso em: 9 jun. 2021

GOMES, Vitor Hugo M.; DUTRA, Rodrigo; NASCIMENTO, Weverson; FERREIRA, Luiz C.; SILVA, Marcelino S. da; KLAUTAU, Aldebaro B. R.; PEREIRA, Antônio. Modelo Georreferenciado de Disponibilidade de Internet para Educação Superior Online: estudo de Caso no Estado do Pará. In: Seminário Integrado De Software E Hardware (SEMISH), 48., 2021, Evento Online. Anais [...]. Porto Alegre: Sociedade Brasileira de Computação, 2021. p. 144-154. ISSN 2595-6205. DOI: https://doi.org/10.5753/semish.2021.15817.

GRANJEIRO, E. M.; MUSSE, J. O, PEIXOTO, T. M.; NUNES, I. V.; SOARES, I. M. S. C.; SILVA, I. C. O.; CARVALHO, T. B.; DIAS, Y. O. Estratégias de ensino à distância para a educação interprofissional em saúde frente à pandemia COVID-19. REVISA, v. 9, Esp.1, p. 591-602, 2020. DOI: https://doi.org/10.36239/revisa.v9.nesp1.p591a602.

GUSSO, H. L.; ARCHER, A. B.; LUIZ, F. B; SAHAO, F. T.; LUCA, G. G.; HENKLAIN, M. H. O.; PANOSSO, M. G.; KIENEN, N.; BELTRAMELLO, O.; GONCALVES, V. M. Ensino superior em 


\section{RECIMA21 - REVISTA CIENTÍFICA MULTIDISCIPLINAR ISSN 2675-6218}

tempos de pandemia: diretrizes à gestão universitária. Educação \& Sociedade [online], v. 41, e238957, 2020. Disponível em: https://doi.org/10.1590/ES.238957. Acesso em: 25 jun. 2021

HARERIMANA, A.; WICKING, K.; BIEDERMANN, N.; YATES, K. Integrating nursing informatics into undergraduate nursing education in Africa: A scoping review. International Nursing Review, p. 1-14, 2020. Disponível em: https://onlinelibrary.wiley.com/doi/full/10.1111/inr.12618.

KHALIL, R.; MANSOUR, A. E.; FADDA, W. A.; ALMISNID, K.; ALDAMEGH, M.; AL-NAFEESAH, A.; ALKHALIFAH, A.; AL-WUTAYD, O. The sudden transition to synchronized online learning during the COVID-19 pandemic in Saudi Arabia: a qualitative study exploring medical students' perspectives. BMC Med Educ, v. 285, 2020. Disponível em: https://bmcmededuc.biomedcentral.com/articles/10.1186/s12909-020-02208-z. DOI: https://doi.org/10.1186/s12909-020-02208-z.

LIRA, A. L. B. C.; ADAMY, E. K; TEIXEIRA, E.; SILVA, F. V. Nursing education: challenges and perspectives in times of the COVID-19 pandemic. Revista Brasileira de Enfermagem [online], v. 73, suppl 2, e20200683, 2020. Disponível em: https://doi.org/10.1590/0034-7167-2020-0683. Acesso em: 25 jun. 2021. Epub 26 Out 2020. ISSN 1984-0446. https://doi.org/10.1590/0034-7167-2020-0683.

MAGALHÃES, A. J. A.; ALMEIDA, M. H. R.; SANTOS, S. C.; BORGES, C. D.; MELO, G. J. C. M.; ALVES, M. D. F. O Ensino da Anamnese Assistido por Tecnologias Digitais durante a Pandemia da Covid-19 no Brasil. Revista Brasileira de Educação Médica [online], v. 44, n. Suppl 01, 2020. Disponível em: https://doi.org/10.1590/1981-5271v44.supl.1-20200437. Acesso em: 25 jun 2021.

MEDEIROS, Arthur de Almeida et al. Analysis of physical therapy education in Brazil during the COVID-19 pandemic. Fisioterapia em Movimento [online], v. 34, e34103, 2021. Disponível em: https://doi.org/10.1590/fm.2021.34103. Acesso em: 27 jul 2021.

MÉLO, C. B.; FARIAS, G. D.; MOISÉS, L. de S.; BESERRA, L. R. M.; PIAGGE, C. S. L. D. Remote education in Brazilian federal universities: challenges and adaptations of education during the COVID19 pandemic. Research, Society and Development, [S. I.], v. 9, n. 11, p. e4049119866, 2020. DOI: 10.33448/rsd-v9i11.9866. Disponivel em: https://www.rsdjournal.org/index.php/rsd/article/view/9866. Acesso em: 19 jul. 2021.

MOURA, Ionara Holanda; SOUSA, Roseanne de Nobre; ALVES, Ramiro Marx Cortez; CAMPELO, Viriato; FREIRE, Suyanne de Macêdo; VILAROUCA, Ana Roberta da Silva. Qualidade de vida de estudantes de graduação em enfermagem. Revista Gaúcha de Enfermagem [online], v. 37, n. 02, e55291, 2016. Disponível em: https://doi.org/10.1590/1983-1447.2016.02.55291. Acesso em: 25 jun 2021.

NATIVIDADE, M. S.; BERNARDES, K.; PEREIRA, M.; SILVA, S. M.; BERTOLDO, J.; TEIXEIRA, M. G.; LAGO, H. L.; ARAGÃO, E. Distanciamento social e condições de vida na pandemia COVID-19 em Salvador-Bahia, Brasil. Ciência \& Saúde Coletiva [online], v. 25, n. 9, p. 3385-3392, 2020. ISSN 1678-4561. Disponível em: https://doi.org/10.1590/1413-81232020259.22142020. Acesso em: 26 jun 2021. DOI: https://doi.org/10.1590/1413-81232020259.22142020.

NETO, F. R. G. X.; MUNIZ, C.; DIAS, L.; SANTOS, F.; SILVA, M.; OLIVEIRA, E. Perfil sociodemográfico dos estudantes de enfermagem da universidade estadual vale do Acaraú (uva). Enfermagem em Foco, [S. I.], v. 8, n. 3, nov. 2017. ISSN 2357-707X. Disponível em: http://revista.cofen.gov.br/index.php/enfermagem/article/view/1532. Acesso em: 25 jun. 2021. DOI: https://doi.org/10.21675/2357-707X.2017.v8.n3.1532.

NEUPANE, H. C.; SHARMA, K.; JOSHI, A. Readiness for the Online Classes during COVID-19 Pandemic among Students of Chitwan Medical College. J Nepal Health Res Counc, v. 8, n. 18, 2, p. 

ISSN 2675-6218

316-319, 2020. Disponível em: https://pubmed.ncbi.nlm.nih.gov/32969401/. DOI:

10.33314/jnhrc.v18i2.2725.

NICKLEN, P.; KEATING, J. L.; PAYNTER, S.; STORR, M.; MALONEY, S. Remote-online case-based learning: A comparison of remote-online and face-to-face, case-based learning - a randomized controlled trial. Educ Health, v. 29, p. 195-202, 2016. Disponível em: https://pubmed.ncbi.nlm.nih.gov/28406103/. DOI: 10.4103/1357-6283.204213.

OLUM, Ronald; ATULINDA, Linda; KIGOZI, Edwin; RHODA, Dianah Nassozi; MULEKWA, Alzan; BONGOMIN, FELIX; KIGULI, Sarah. Medical Education and E-Learning During COVID-19 Pandemic: Awareness, Attitudes, Preferences, and Barriers Among Undergraduate Medicine and Nursing Students at Makerere University, Uganda. Journal of Medical Education and Curricular Development, v. 7, p. 1-9, 2020. Disponível em: https://journals.sagepub.com/doi/10.1177/2382120520973212. DOI: https://doi.org/10.1177/2382120520973212.

PARÁ. Fundação Amazônia de Amparo a Estudos e Pesquisas do Pará (FAPESPA). Relatório sobre a Vulnerabilidade Social no Estado do Pará. Belém: Diretoria de Estudos e Pesquisas Socioeconômicas e Análise Conjuntural, 2015. Disponível em: http://www.fapespa.pa.gov.br/upload/Arquivo/anexo/570.pdf?id=1480084947.

PASSERO, G.; WAHLBRINK, N. E. E.; SCARANTO, R. L. D. Uma revisão sobre o uso das TICS na educação da geração Z. Revista Renote, v. 14, n. 2, 2016. Disponível em: https://www.seer.ufrgs.br/renote/article/view/70652/40081. Acesso em: 19 jul. 2021.

RAJAB, M. H.; GAZAL, A. M.; ALKATTAN, K. Challenges to online medical education during the COVID-19 pandemic. Cureus, v. 12, n. 7, p. :e8966, 2020. Disponível em: https://www.ncbi.nlm.nih.gov/pmc/articles/PMC7398724/pdf/cureus-0012-00000008966.pdf. Acesso em: 28 jul. 2021.

RAMOS-MORCILLO, A. J.; LEAL-COSTA, C.; MORAL-GARCÍA, J. E.; RUZAFA-MARTÍNEZ, M. Experiences of Nursing Students during the Abrupt Change from Face-to-Face to e-Learning Education during the First Month of Confinement Due to COVID-19 in Spain. Int J Environ Res Public Health, v. 17, n. 15, p. 5519, jul. 2020. Disponível em: https://www.ncbi.nlm.nih.gov/pmc/articles/PMC7432480/pdf/ijerph-17-05519.pdf. DOI: 10.3390/ijerph17155519

RIBEIRO, Tiago dos Santos; GUALBERTO, Luciano Soares; DIAS, Lucas Soares Machado; SANTANA, Nayara Brito; AUGUSTA, Maria Vasconcelos Palácio; ROCINEIDE, Maria Ferreira da Silva. Uso de aplicativos móveis no processo de ensino-aprendizagem na graduação em enfermagem. Rev baiana enferm, v. 35, p. e37136, 2021. Disponível em: https://periodicos.ufba.br/index.php/enfermagem/article/view/37136/23449.

RIES, E. F.; POSSATTI, V. M. R.; LOPES, C. G. S. Avaliação do ensino remoto de Epidemiologia em uma universidade pública do Sul do Brasil durante pandemia de COVID-19. Scielo preprints, 2020. Disponível em: https://preprints.scielo.org/index.php/scielo/preprint/view/1152/1736. Acesso em: 10 jul. 2021. DOI: 10.1590/SciELOPreprints.1152.

SANTOS, Ana Thaís Santana et al. Integralidade do cuidado na formação do enfermeiro: visões e vivências do acadêmico de enfermagem. Enfermagem em Foco, [S.I.], v. 10, n. 1, fev. 2019. ISSN 2357-707X. Disponível em: http://revista.cofen.gov.br/index.php/enfermagem/article/view/1397/507. Acesso em: 23 jun. 2021. DOI: https://doi.org/10.21675/2357-707X.2019.v10.n1.1397.

SANTOS, Geórgia Maria Ricardo Félix dos, SILVA, Maria Elaine da; BELMONTE, Bernardo do Rego. COVID-19: emergency remote teaching and university professors' mental health. Revista Brasileira 


\section{RECIMA21 - REVISTA CIENTÍFICA MULTIDISCIPLINAR ISSN 2675-6218}

de Saúde Materno Infantil [online], v. 21, n. Suppl 1, p. 237-243, 2021. Available from: https://doi.org/10.1590/1806-9304202100S100013. Accessed 9 June 2021.

SCHMIDT, Beatriz et al. Saúde mental e intervenções psicológicas diante da pandemia do novo coronavírus (COVID-19). Estudos de Psicologia (Campinas) [online], v. 37, e200063, 2020. Disponível em: https://doi.org/10.1590/1982-0275202037e200063. Acesso em: 8 jun. 2021.

SCORSOLINI-COMIN, Fabio; MELO, Lucas Pereira de; ROSSATO, Lucas; GAIA, Ronan da Silva Parreira. Educação a distância na formação em enfermagem: reflexões sobre A pandemia da covid-19. Revista Baiana de Enfermagem, v. 34, e36929, 2020. Disponível em: https://repositorio.usp.br/directbitstream/0a020a66-bb5c-44f7-86d0-ed085ea326c0/003029238.pdf.

SILVA, A. M. A.; MASCARENHAS, V. H. A.; ARAUJO, S. N. M.; MACHADO, R. S.; SANTOS, A. MR.; ANDRADE, E. M. L. R. Mobile technologies in the Nursing area. Rev Bras Enferm [Internet], v. 71, n. 5, p. 2570-8, 2018. Disponível em:

https://www.scielo.br/j/reben/a/5k48Mq64Qp5vnCthC3GGMMq/?lang=pt\#. DOI: http://dx.doi.org/10.1590/0034-7167-2017-0513.

SILVA, A. M. Prática metodológica de ensino centrada no aluno em uma escola da rede pública de São Luís. 2018. 38p. Monografia (Licenciado em Física) - Faculdade de Física, Universidade Federal do Maranhão. São Luís, 2018. Disponível em: https://rosario.ufma.br/jspui/bitstream/123456789/3189/1/ANDRESSA-SILVA.pdf.

SILVA, C. M. B.; MEDEIROS, B. V. C.; IWANAMI, K. A.; ASSED, T. T. B. COVID-19. E o direito à educação: alargamento da desigualdade educacional. In.: Anais do Encontro Virtual de Documentação em Software Livre e Congresso Internacional de Linguagem e Tecnologia Online, [S. I.], v. 9, n. 1, nov. 2020. ISSN 2317-0239. Disponível em: http://www.periodicos.letras.ufmg.br/index.php/anais_linguagem_tecnologia/article/view/17788/11256 13729. Acesso em: 14 jul. 2021.

SILVA, C. M.; TORIYAMA, A.T. M.; CLARO, H. G.; BORGHI, C. A.; CASTRO T. R.; SALVADOR, P. I. C. A. Pandemia da COVID-19, ensino emergencial à distância e Nursing Now: desafios à formação em enfermagem. Revista Gaúcha de Enfermagem, v. 42, e20200248, 2021. Disponível em: DOI: https://doi.org/10.1590/1983-1447.2021.2020024.

SILVA, F. C.; ZAMPROGNA, K. M.; SILVA, S. S.; HEMKEMEIER, D. S.; SELL, Denilson. Social isolation and the speed of covid-19 cases: measures to prevent transmission. Revista Gaúcha de Enfermagem [online], v. 42, n. spe, 2021, e20200238. Disponível em: https://doi.org/10.1590/19831447.2021.20200238. Acesso em: 23 jun. 2021.

SILVA, Ivoneide Mendes da; LINS, Walquíria Castelo Branco; LEAO, Marcelo Brito Carneiro. Avaliação da aplicação da metodologia aprendizagem baseada em problemas na disciplina de tecnologia da informação e comunicação no ensino de química. Educ. quím, Ciudad de México, v. 30, n. $3, \quad$ p. $64-78, \quad 2019 . \quad$ Disponible en: http://www.scielo.org.mx/scielo.php?script=sci arttext\&pid=S0187893X2019000300064\&lng=es\&nrm=iso. Accedido en: 09 jun. 2021.

SILVEIRA, A.; OLIVEIRA, N. S.; ANTUNES, L. W; SIEPMANN, K. L. S.; TISOTT, Z. L.; ALENDE, L. P. Estratégias e desafios do ensino remoto na Enfermagem. Enfermagem em Foco, [S. I.], v. 11, n. 5, mar. 2021. ISSN 2357-707X. Disponível em: http://revista.cofen.gov.br/index.php/enfermagem/article/view/4302. Acesso em: 25 jun. 2021. DOI: https://doi.org/10.21675/2357-707X.2020.v11.n5.4302. 


\section{RECIMA21 - REVISTA CIENTÍFICA MULTIDISCIPLINAR ISSN 2675-6218}

SINGH, Fiona; MASANGO, Thembekile. Information Technology in Nursing Education: Perspectives of Student Nurses. The Open Nursing Journal, v. 14, p. 18-28, 2020. Disponível em: https://opennursingjournal.com/VOLUME/14/PAGE/18/FULLTEXT/.

SINGH, H. K.; JOSHI, A.; MALEPATI, R. N.; NAJEEB, S.; BALAKRISHNA, P.; PANNERSELVAM, N. K.; SINGH, Y. K.; GANNE, P. A survey of E-learning methods in nursing and medical education during COVID-19 pandemic in India. Nurse Educ Today, Apr;v. 99, p.104796, apr. 2021. Disponível: https://pubmed.ncbi.nIm.nih.gov/33607513/. DOI: 10.1016/j.nedt.2021.104796.

STUART, Werlayne Soares-Leite et al. A inclusão das TICs na educação brasileira: problemas e desafios. Revista Internacional de Investigación en Educación, v. 5, n. 10, p. 173-187, 2012. Disponível em:

http://repositorio.minedu.gob.pe/bitstream/handle/20.500.12799/2600/A\%20inclus\%c3\%a3o\%20das\% 20TICs\%20na\%20educa\%c3\%a7\%c3\%a3o\%20brasileira\%20problemas $\% 20$ e $\% 20$ desafios.pdf?sequ ence=1\&isAllowed=y. Acesso em: 22 jul. 2021.

SOY-MUNER, D. Continuous learning through platforms. Farm Hosp, v. 44, Supl 1, p. S71-3, 2020. Disponível em: http://www.aulamedica.es/fh/pdf/11488.pdf. Acesso em: 25 jun. 2021.

THEORET, Cara; MING, Xue. Our education, our concerns: the impact on medical student education of COVID-19. Med Educ, v. 54, n. 7, p. 591-2, 2020. Disponível em:

https://www.ncbi.nlm.nih.gov/pmc/articles/PMC7264564/pdf/MEDU-9999-na.pdf. Acesso em: 15 jun. 2021.

UNESCO. A Comissão Futuros da Educação da Unesco apela ao planejamento antecipado contra o aumento das desigualdades após a COVID-19. Paris: Unesco, 2020. Disponível em: https://pt.unesco.org/news/comissao-futuros-da-educacao-da-unesco-apela-ao-planejamentoantecipado-o-aumento-das.

VALENTE, G. S. C.; MORAES, Érica B. de.; SANCHEZ, M. C. O.; SOUZA, D. F. de.; PACHECO, M. C. M. D. Remote teaching in the face of the demands of the pandemic context: Reflections on teaching practice. Research, Society and Development, [S. I.], v. 9, n. 9, p. e843998153, 2020. Disponível em: https://www.rsdjournal.org/index.php/rsd/article/view/8153. Acesso em: 19 jul. 2021. DOI: $10.33448 /$ rsd-v9i9.8153.

VATIER, C.; CARRIÉ, A.; RENAUD, M. C.; T, N. S.; HERTIG, A.; JÉRU, I. Lessons from the impact of COVID-19 on medical educational continuity and practices. Adv Physiol Educ, v. 45, p. 390-398, 2021. Disponível em: https://journals.physiology.org/doi/full/10.1152/advan.00243.2020. DOI:10.1152/advan.00243.2020.

VIANNA, Thaysa Vieira de Mello Gomes de Azevedo. Uma análise sobre a expansão do ensino de enfermagem no Brasil. 2019, 56 f. Dissertação (Mestrado Profissional em Educação Profissional em Saúde) - Escola Politécnica de Saúde Joaquim Venâncio, Fundação Oswaldo Cruz, Rio de Janeiro, 2019.

VIEIRA, K. M.; POSTIGLIONI, G. F.; DONADUZZI, G.; PORTO, C. dos S.; KLEIN, L. L. Vida de Estudante Durante a Pandemia: Isolamento Social, Ensino Remoto e Satisfação com a Vida. EaD em Foco, v. 10, n. 3, set. 2020. Disponível em:

https://eademfoco.cecierj.edu.br/index.php/Revista/article/view/1147/574.

WIERSINGA, W. J.; RHODES, A.; CHENG, A. C.; PEACOCK, S. J.; PRESCOTT, H. C. Pathophysiology, Transmission, Diagnosis, and Treatment of Coronavirus Disease 2019 (COVID-19). JAMA, 2020. doi:10.1001/jama.2020.12839. 